\title{
0811 CAR SAFETY RESTRAINT USE AMONG CHILDREN IN CATALONIA. WHAT CAN BE DONE FROM THE HEALTH SECTOR?
}

J M Suelves, V Martinez-Beneyto*, A Medina, C Cabezas, A Plasencia, P Brugulat, R Tresserras Correspondence: Department of Health, Government of Catalonia, Travessera de les Corts, 131-159 Barcelona (Spain), Spain

10.1136/ip.2010.029215.811

In Catalonia (Spain), injuries due to motor vehicle crashes caused 383 hospital admissions among children aged $0-14$ in 2007. The use of appropriate safety restraints is compulsory for all automobile occupants according to Spanish regulations, as it may reduce the number and severity of these injuries. According to the Catalan Health Survey carried out in 2006, at least $88.8 \%$ of parents or caregivers of children aged $0-14$ who travelled by car in the previous year reported that an appropriate safety restraint was always used. Variables related to the use of safety restraints, included children age (5- to 9-year-olds used restraints less often than other age groups), family socioeconomic level, and educational level of mothers. To increase the use of car safety restraints among children and adolescents, the Catalan road safety administration develops media campaigns and law enforcement activities. Health professionals and administrations must also play a complementary role in this field giving advice about the selection of appropriate restraints and managing children resistance to use them. The recent development and implementation of safety restraint promotion activities in Catalonia is shown in this presentation, including the release of a media campaign addressed to young children, and the dissemination of educational materials addressed to families in the context of paediatric health education activities. 